\title{
EDUCAÇÃO EM ENGENHARIA ENVOLVENDO A CONSTRUÇÃO DE UMA ESTUFA AGRICOLA COMO DEMANDAS DA EXTENSÃO
}

DOI: 10.37702/2175-957X.COBENGE.2021.3630

Elias Antunes dos Santos - eliasantunes@unemat.br

UNEMAT

Rua Domingos Germano de Souza 1101

78300-000 - Tangará da Serra - MT

Marinez Cargnin-Stieler - marinez@unemat.br

UNEMAT

Rua 21890

78300-000 - Tangará da Serra - MT

SERGIO CAMARGO - s1.camargo@gmail.com

UFPR

R. Eduardo Aguirre Calabresi 161

80050-390 - Diamante d'Oeste - PR

Resumo: Relata-se a construção de uma estufa agrícola como uma atividade prática e extensionista com o intuito também de que os alunos estejam no centro da aprendizagem, com pensamento livre, capacidade crítica, vocação inovadora e empreendedora, interação física com pares. A ideia inicial foi oferecer condições mais apropriadas para ocorrer a aprendizagem e incentivar os alunos matriculados nas disciplinas de Física do curso de Engenharia Civil da Universidade do Estado de Mato Grosso (UNEMAT), Campus Universitário Prof. Eugênio Carlos Stieler em Tangará da Serra. $O$ ensino-aprendizagem exige um constante repensar sobre como ensinar para que os alunos tenham prazer com o aprendizado e sintam-se desafiados em adquirir conhecimentos, consciência crítica e social para melhor viver em sociedade. As Novas DCNs das engenharias estimulam o uso de metodologias que favoreçam a aprendizagem ativa, como forma de promover uma educação mais centrada no aluno. Os documentos analisados foram os relatórios, as entrevistas, as imagens e as observações fornecidas pelos professores que acompanharam as ações e a apresentação pública do trabalho. As ações foram avaliadas positivamente, elencaram o aprendizado, o conhecimento, o trabalho em grupo a integração e apoio. O olhar dos alunos foi de admiração, contentamento e sentiram-se realizados pela capacidade que adquiriram em planejar, projetar, orçar 


\section{(C. COBENGE de Educação em Engenharia

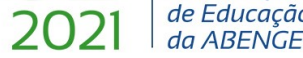 28 a 30 de SETEMBRO

e executar a obra envolvendo a construção de uma estufa.

Palavras-chave: Ensino-aprendizagem. Aprendizagem ativa. Consciência crítica e social 


\section{EDUCAÇÃO EM ENGENHARIA ENVOLVENDO A CONSTRUÇÃO DE UMA ESTUFA AGRICOLA COMO DEMANDAS DA EXTENSÃO}

\section{INTRODUÇÃO}

Neste artigo descreve-se a construção de uma estufa como uma atividade prática e extensionista com o intuito também de que os alunos estejam no centro da aprendizagem e realizem as atividades com suas próprias mãos - 'mãos na massa'. A estufa tem sido uma demanda social no município por sua vocação agrícola e uma forma de incentivar a aprendizagem dos alunos.

Construir algo pode ser uma estratégia pedagógica que orienta a formação de um engenheiro com pensamento livre, capacidade crítica, vocação inovadora e empreendedora, interação física com pares, de acordo com as necessidades num contexto globalizado, na qual a fundamentação teórica e científica se integra com a inovação, criatividade e a prática (METAUTE PANIAGUA, et al., 2018).

A ideia inicial foi oferecer condições mais apropriadas para ocorrer a aprendizagem e incentivar os alunos matriculados nas disciplinas de Física do curso de Engenharia Civil da Universidade do Estado de Mato Grosso (UNEMAT), Campus Universitário Prof. Eugênio Carlos Stieler em Tangará da Serra. As atividades foram orientadas e realizadas durante o semestre letivo. Algumas questões iniciais permearam as discussões com 0 corpo discente como por exemplo: Como ser engenheiro civil e proporcionar melhores condições de vida para a comunidade? Quais as oportunidades para os engenheiros civis dentro do Estado, município ou país? A proposição temática para o grupo foi a realização de um trabalho inovador, duradouro, útil e relacionados a projetos e execução na construção civil, portanto no contexto da Engenharia Civil.

O ensino-aprendizagem exige um constante repensar das maneiras/formas de como ensinar para que os alunos sintam prazer com o aprendizado e adquirir conhecimentos, que reduzam as evasões e as reprovações e ainda auxiliam para que os alunos adquiram consciência crítica e social para melhor viver em sociedade. Ensinar é contribuir para a compreensão dos conhecimentos, procedimentos e valores que permitam aos alunos tomar decisões assertivas e perceber como a ciência pode melhorar a qualidade de vida do ser humano (CHASSOT, 2003).

Utilizar metodologias inovadoras no processo de ensino-aprendizagem para instigar os alunos a realizarem ações, incentivá-los a aprender tornando-os protagonistas de sua própria aprendizagem, participando de forma ativa em seu processo formativo. Essas metodologias de ensino-aprendizagem exigem do professor maior disponibilidade e busca de conhecimentos pois desde o início o professor não está com o controle das ações e sim é um orientador das atividades, um facilitador, os alunos decidem o que e como será suas ações. O aprendizado segue as ações do grupo, e as buscas que cada um pode oferecer e compartilhar para a realizar a atividade.

Existem demandas recentes nos cursos de Engenharia que podem incentivar os alunos e professores para uma educação mais ativa (CARGNIN-STIELER, 2014), pode-se citar também as Novas DCNs das engenharias que estimulam o uso de metodologias que favoreçam a aprendizagem ativa, como forma de promover uma educação mais centrada no aluno (BRASIL, 2019) e que façam parte da realidade dos envolvidos. As diretrizes estão 
organizadas por competências e com atividades práticas que os conteúdos sejam ampliados e que também possam ampliar as competências. Ainda que as atividades práticas tragam significância e prazer em aprender. As DCNs orientam que os cursos oportunizam o engenheiro ser um agente inovador na sociedade. As DCNs são implantadas nos cursos por um processo de articulação e institucionalização (CURI, 2020).

Diante da realidade temos trabalhado com o intuito que os alunos no curso de Engenharia Civil desde os semestres iniciais, nas disciplinas que compõe a matriz curricular, consigam adquirir atitudes proativas que os permitam a reflexão e que possibilite perceber a inovação no uso e aprimoramento de tecnologias que envolvam o processo construtivo.

Essas atividades práticas no Campus iniciaram-se em 2015 e foram ganhando corpo e forma diferenciada de trabalhar também pela experiencia dos professores e pelos conhecimentos adquiridos. Vale ressaltar que a cada semestre letivo os trabalhos foram aprimorados principalmente pelo acompanhamento, orientação e o despertar para a função social dos trabalhos desenvolvidos pelos acadêmicos (SANTOS, CARGNIN-STIELER, WEBER, 2019a; SANTOS, CARGNIN-STIELER, WEBER, 2019b; SANTOS, CARGNINSTIELER, DAMASCENO, 2019)

Para o professor de Física, no curso de Engenharia Civil os assuntos a respeito da área eram de melhor compreensão, existia afinidade com a área em relação as outras engenharias. Outra vantagem foi trabalhar como docente em um único Campus em um único curso.

Com as mudanças nos currículos sugeridas pelas DCNs é possível afirmar que essas formas de trabalho encontram respaldo nas DCNs, nos Projetos Pedagógicos do Curso e na literatura pesquisada. Diante do exposto acredita-se que seja necessário mudar a forma de trabalhar os conteúdos de Física, tendo um foco maior nos conceitos relacionados as propriedades dos materiais. Sendo assim, faz-se necessário pensar formas de gerir os estudos desses alunos, isso exige mudanças estruturais sejam físicas que forneçam condições dos estudantes estarem no Campus em plena atividade. Aponta-se como uma estratégia as empresas juniores, o uso de tecnologias para gestão de tarefas e leituras. Os professores, os cursos e as faculdades precisam pensar colaborativamente trabalho em equipes. É necessário pensar em projetos que permitam trabalhar de forma conjunta. Acredita-se que esses ideais estão de acordo com Nóvoa (2009) e os saberes são construídos pela troca de experiencias durante a trajetória do trabalho docente.

O Campus apresenta algumas demandas infra estruturais como reformas e construção de estufas para o curso de Agronomia que podem ser percebidas como uma oportunidade para os alunos de engenharia empreenderem em função das demandas no setor hortifruti. Essas demandas inclusive poderiam ser atividades que os alunos consigam se envolver na busca de soluções para esse tipo de estrutura. Essas ações podem possibilitar aos envolvidos a experienciação da relação teoria e prática de conceitos de Física no processo de ensino-aprendizagem no curso Engenharia além de questões vinculadas a problemáticas locais, ou seja, da comunidade em geral.

Nesse contexto, apresenta-se algumas experiências vivenciadas com estudantes envolvendo a temática do processo de construção de uma estufa agrícola.

\section{CONTEXTUALIZAÇÃO DO ESTUDO}

As atividades foram desenvolvidas na Universidade do Estado de Mato Grosso (UNEMAT), no Campus Universitário em Tangará da Serra, no Curso de Engenharia Civil. A UNEMAT, com sede na cidade de Cáceres, foi pensada como uma universidade do 
interior do Estado do Mato Grosso para o interior do Estado. Conta com 13 Campus distribuídos em diferentes cidades do interior (Figura 1). Oferece as modalidades regular, parceladas, a distância e indígena. A UNEMAT tem um sistema de cotas e ações afirmativas. Oferece cinco cursos de Engenharia em cinco Campus.

Figura 1: Mapa do Estado de Mato Grosso e os municípios sede dos Campus.

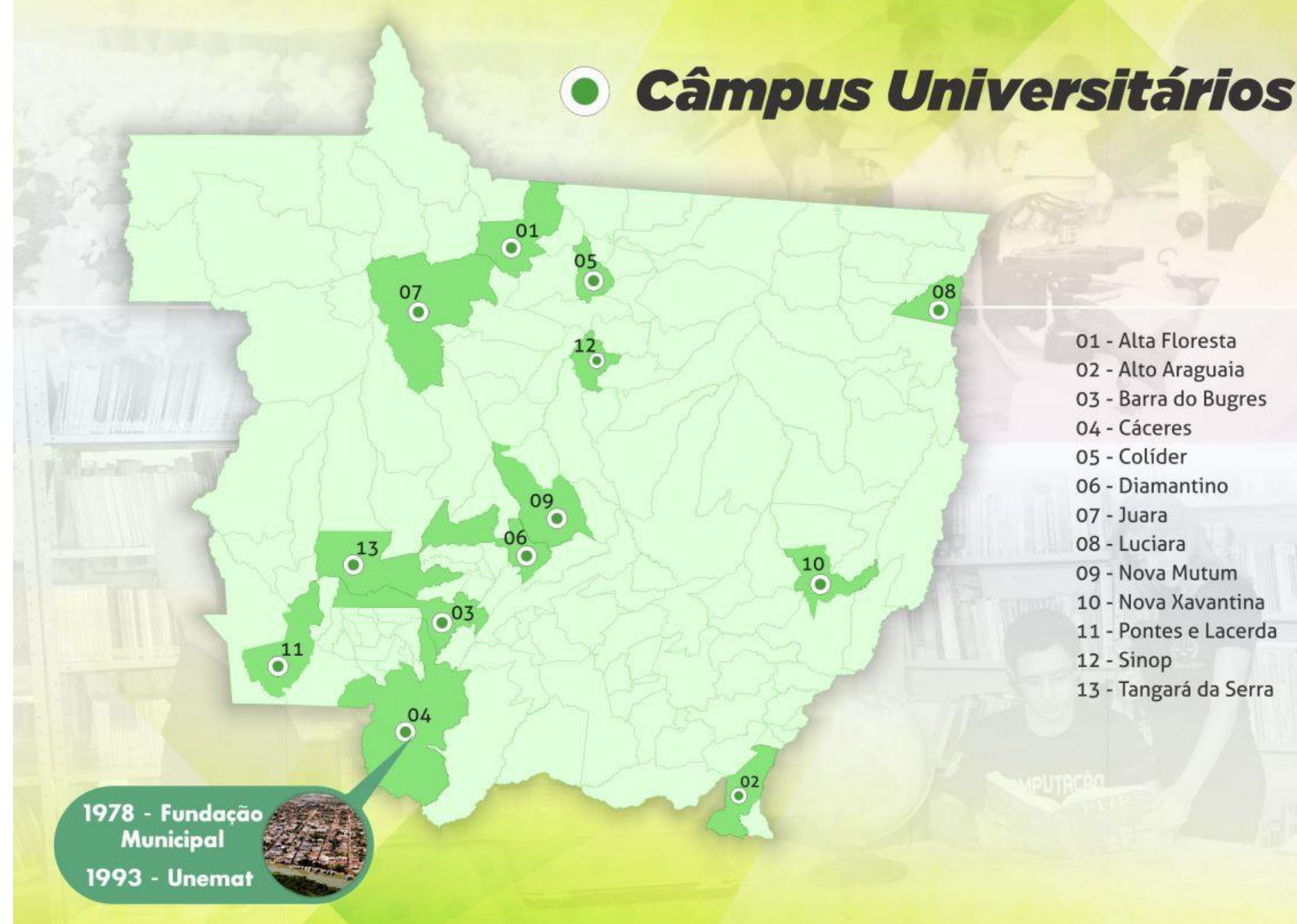

Fonte: UNEMAT, 2021

O Campus em Tangará da Serra (Figura 1, Campus 13), oferta oito cursos regulares de graduação entre eles Engenharia Civil e Agronomia. O Campus completou 25 anos de existência em 2020.

O Curso de Engenharia Civil é um curso totalmente presencial, em período integral e diurno, formou a primeira turma em 2017/2. Para o curso, a UNEMAT oferta duas entradas anuais com 40 alunos por semestre via Sisu ou vestibular e são oriundos do território nacional. As disciplinas são ofertadas por semestres e no máximo com 48 alunos por turma. É importante destacar a propósito de contextualização que Tangará da Serra é um município com pouco mais de cem mil habitantes, essencialmente agrícola. Juntamente com outros municípios da região comporta um dos maiores assentamento da Reforma Agrária.

A cidade possui uma das maiores feiras do produtor, ou seja, dois espaços cobertos que ocupam dois quarteirões onde se comercializam produtos hortifrutigranjeiro. Os produtores têm interesse em ofertar produtos de qualidades. No entanto, o clima tropical apresenta estiagem e período das chuvas. Ambos os períodos precisam de espaços como estufas para uma boa produção, ora por falta de água, ora por excesso, além das 
intempéries e as patologias. Esses produtores podem contar com assistência técnica, inclusive com mudas do MT Horticultura em parceria com a prefeitura municipal, no entanto a questão das estufas limita a qualidade de alguns produtos.

Ressalta-se que, para vários produtores a construção de estufas se torna inviável pelo custo da implantação. Portanto, esse trabalho tem um cunho também social por ampliar as possibilidades de produção de hortifrutigranjeiro da região

\section{METODOLOGIA}

Este trabalho de caráter extensionista foi realizado no âmbito das disciplinas de Física do curso de Engenharia Civil da Universidade do Estado de Mato Grosso (UNEMAT) em Tangará da Serra. O objetivo principal foi a construção de estufa como uma prática extensionista. A ideia com a proposição da construção da estufa foi envolver os alunos com atividades práticas e colocá-los no centro do processo de ensino-aprendizagem.

Nesse sentido, para a realização das atividades, inicialmente o professor de Física instigou seus alunos a buscarem soluções para as demandas estruturais encontradas no Campus para planejarem e executarem uma ação. Após uma conversa "aparentemente informal", o professor solicitou aos alunos que em pequenos grupos ou individualmente "caminhassem" pelo Campus para fazer suas observações e discutir em sala suas percepções sobre o Campus.

Os alunos, orientados pelo professor se organizaram em pequenos grupos para planejar e executar as atividades. A ideia, o pré-projeto, um projeto, as atividades, ou seja, as ações e execuções do projeto, e por último a apresentação dos resultados incluindo um relatório sobre o que foi desenvolvido.

Os grupos são acompanhados pelo professor(es) e durante as atividades, entrevistados por professores pesquisadores através de um roteiro semiestruturado (Quadro 1). As entrevistas são gravadas e/ou filmadas.

Quadro 1: Recorte do formulário para a entrevista com os alunos.

1. Quais os interesses que o levaram buscar este trabalho?

2. Como foi o planejamento do trabalho?

3. Como foi a execução do trabalho?

4. Como foi a integração do Grupo?

5. Quais conhecimentos/habilidades foram adquiridos/desenvolvidos tanto para a vida como para a engenharia?

6. Quais disciplinas/conteúdos que você(s) conseguiram se valer durante as atividades?

7. Que conhecimentos das disciplinas cursadas nos semestres anteriores foram utilizados?

8. Que conteúdos/disciplinas que ainda não cursaram precisaram buscar/estudar?

9. Fale sobre a vivência do trabalho.

10. Quais os pontos positivos do trabalho?

11. Quais conclusões que foi possível encontrar durante a execução das atividades?

12. Quais as principais decisões que precisaram tomar?

13. O que embasou as decisões tomadas?

14. Fale sobre o relatório

Fonte: Arquivo pessoal dos autores

Os documentos analisados foram os relatórios, as entrevistas, as imagens e as observações fornecidas pelos professores que acompanharam as ações e a apresentação pública do trabalho final. 


\section{$4 \quad$ RESULTADOS}

Os alunos instigados pelo professor buscaram algo que pudessem encontrar e desenvolver. No relatório, os alunos desse grupo descrevem que "o primeiro desafio foi escolher um tema para desenvolver, pois esse teria que ser algo inovador, duradouro, útil, poderia ser uma reforma de outros projetos, e o principal, ter relação com construção para que não fugisse da área de Engenharia Civil" (Relatório A, 2018, p. 4).

Após decidirem o que fazer, para o grupo era um propósito desafiador, começaram a investigar suas ações. Entre outros questionamentos está: Como é possível construir uma estufa com custo acessível para os pequenos agricultores do município?

O grupo de alunos escreveu em seu relatório que "a ideia surgiu a partir de uma aula de Física, em que no final dessa o professor levou os alunos para caminhar pela UNEMAT, dar ideias, inspirar e debater sobre possíveis temas" (Relatório A, 2018, p. 4).

O professor sabia que existia a demanda das estufas oriundas do curso de Agronomia, denominado Programa de Extensão MT Horticultura e que trabalhavam com melhoramento genético cuja principal atividade extensionista é assessorar os produtores de hortifrutigranjeiros com atividades de campo e subsídio de assessoria técnica fornecimento de mudas. O Grupo tem como missão "atender os produtores de frutas, flores e hortaliças com informação, orientação e assistência técnica, a partir de pesquisas desenvolvidas na universidade" (MT Horticultura, UNEMAT, 2021).

Entretanto no relatório os alunos descrevem "Ao avistar as estufas usadas pelo curso de Agronomia, algumas precisando de reforma, uma integrante do grupo viu a oportunidade, levou essa ideia ao grupo, a qual foi acatada com sucesso" (Relatório A, 2018, p. 4).

A partir de pesquisas bibliográficas e instigados pelo professor, os alunos começaram os primeiros ensaios sobre como construir uma estufa. A primeira ideia surgiu de uma aluna que ao visitar o Campus se deparou com uma estufa em condições precárias. A partir dessa observação um grupo se organizou e começaram a investigar. Ao procurarem pelos professores do curso de Agronomia, conversaram com o professor responsável se havia a possibilidade de conseguir o material necessário para a construção. A partir dessa conversa inicial começaram a buscar forma de construir a estufa, desde o projeto até a conclusão da obra.

O grupo conseguiu manter o interesse em desenvolver essa ação, se valeram de conhecimentos adquiridos e precisaram buscar novos conhecimentos. Os alunos estavam sob orientação do professor de Engenharia Civil e do professor de Agronomia e procuraram outros professores e colegas de semestre finais para compreender como poderiam desenvolver as ações a contento.

Algumas ideias ficaram no papel, foram planejadas e não executadas até porque os interesses do curso que receberia a estufa e do objetivo da estufa também contaram na hora de executar a ação.

Como outros trabalhos desenvolvidos em anos anteriores foi organizado uma apresentação pública na Universidade e os resultados foram divulgados (SANTOS; CARVALHO; CARGNIN-STIELER, 2016).

O próximo passo foi pensar na construção de estufa que se destinassem a pequenos produtores. Como efetuar essas ações em assentamentos ou a outros pequenos produtores que necessitassem de estufa? Quais são os materiais e os processos de construção necessárias que poderiam trazer melhores resultados? Além da qualidade, foi pensado na estética do produto (interesse arquitetônico) e nas normas técnicas (NBR 16032). 
Os alunos foram acompanhados e entrevistados durante as atividades e na conclusão dos trabalhos por professores pesquisadores.

\subsection{Construção da estufa}

As ações para a construção da estufa estão descritas a seguir. A primeira ação foi conhecer a estufa, que foi apresentada pelo professor do curso de Agronomia, quais as necessidades, os problemas enfrentados (Figura 2). Foram discutidas as ações a serem desenvolvidas.

Figura 2: Vista lateral da estufa antiga construída em madeira e interior da estufa

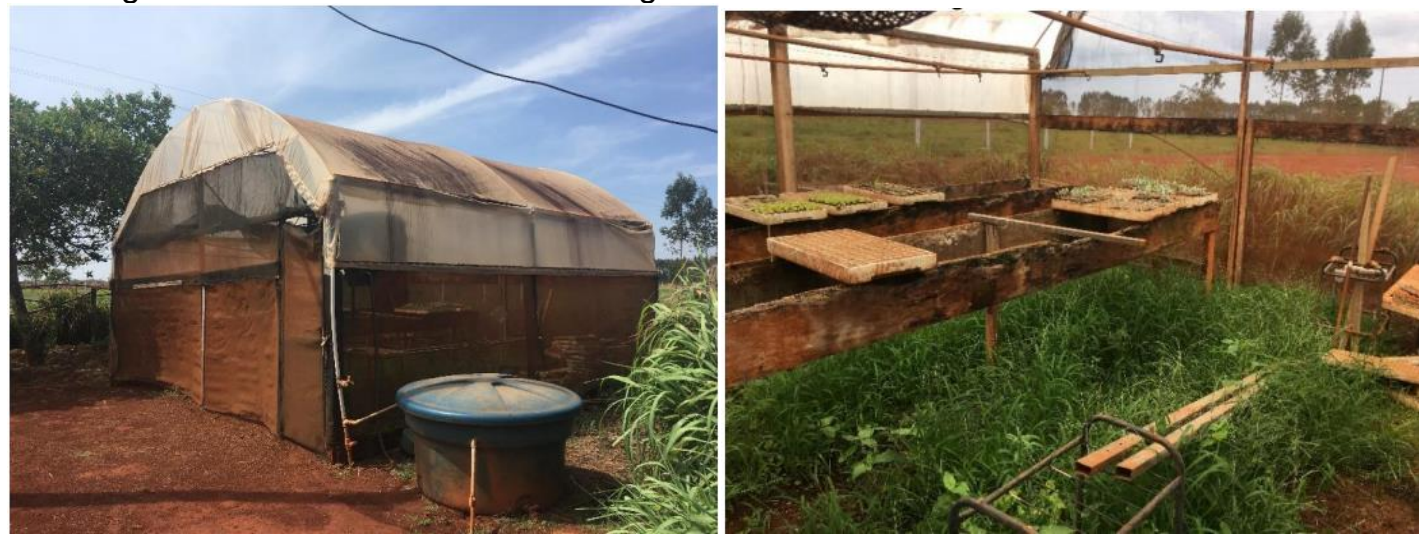

Fonte: Relatório A p. 5 e 6

A estufa foi construída no mesmo espaço e com as mesmas dimensões da anterior. Após o levantamento de dados para o dimensionamento, os alunos fizeram um projeto usando softwares de desenho e posteriormente apresentaram a maquete eletrônica da estufa para o professor de Agronomia e foram discutidas as possibilidades e ações necessárias (Figura 3).

O professor de Engenharia Civil orientou que o Grupo realizasse um levantamento de todos os materiais necessários para a construção de uma estufa. A partir dessas informações seria possível criar uma planilha como perspectiva financeira. Com isso poderia ter uma estimativa de custos.

Figura 3: Maquete 3D da estufa e estufa

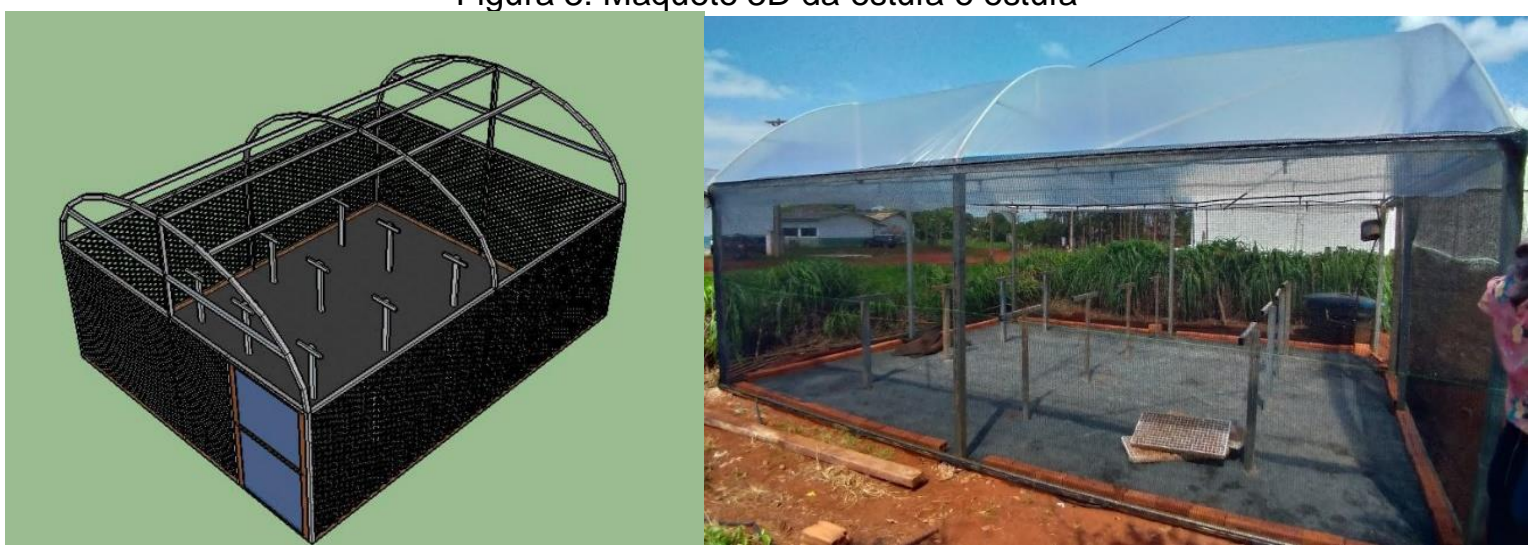

Fonte: Relatório A p.8 e arquivo pessoal dos autores

No relatório os alunos do Grupo elencaram onze ações sendo: Conhecer a estufa de madeira, medição e projeto, desamarração e pintura, pintura e vão, nivelamento, perímetro 
com tijolos de oito furos, irrigação, colocação do pó de brita, pó de brita e telamento. Ou seja, os alunos, por etapas descreveram suas ações.

No relatório, os resultados obtidos são outro subitem. Começam por descrever a instigação do professor que foi construir uma estufa com custos acessíveis para pequenos agricultores.

\subsection{Avaliação dos trabalhos realizados}

Nesta seção analisa-se as avalições que o grupo e os professores realizaram seja no relatório, nas entrevistas, nas observações.

As ações foram avaliadas positivamente, elencaram o aprendizado, o conhecimento, o trabalho em grupo a integração e apoio dos alunos inclusive do curso Agronomia.

Citaram que buscaram soluções e alternativas para otimizar custos. Precisaram tomar decisões, foi discutido e precisaram buscar conhecimentos, conversar com os professores e colegas. As trocas de ideias favoreceram o aprendizado.

Os alunos elencaram como interesse em construir a estufa, a possibilidade de auxiliar outro curso, a demanda do setor de hortifruti granjeiro, o acolhimento do curso receptor, e o aprendizado que poderiam adquirir com a construção. O planejamento do trabalho foi facilitado pela orientação, acompanhamento dos professores e pela facilidade em projetar antes de construir. A execução do trabalho foi uma tarefa que demandou conhecimento, experiência e se sentiram seguros com a orientação e acompanhamento dos professores de ambas áreas e cursos.

Quanto a integração, relatam ter sido facilitada pelo interesse na ação desenvolvida, foi o primeiro trabalho prático construído na área de engenharia desenvolvido pelo grupo e isso trouxe contentamento em ver os resultados obtidos. Durante o desenvolvimento das ações os alunos perceberam que foi uma oportunidade como futuros engenheiros por poder contribuir com uma demanda social dos produtores da região. Ao acompanhar os trabalhos, foi possível perceber que os alunos estavam mudando o olhar a respeito da atividade que envolvia a construção da estufa. Perceberam também novos horizontes no ramo de inovação e prestação de serviço em uma demanda regional. $\mathrm{Na}$ entrevista os alunos referem-se "A gente vê algo sendo construído é diferente de construir" (Entrevista, 2018/Aluno A). "e aqui enfrentamos desafios que vamos enfrentar lá fora, agora não lembro outro exemplo, então encher uma carriola de pedrisco e querer empurrar, se colocar metade será mais fácil" (Entrevista, 2018/Aluna B). Seguem argumentando sobre a motivação para construir e perceberam uma oportunidade. "O professor falava vocês não estão construindo uma estufa, vocês estão construindo uma maneira mais barata de construir uma estufa" (Entrevista, 2018/Aluno C).

Quanto aos conhecimentos e habilidades adquiridas listaram desde o fortalecimento das amizades até o gosto em aprender e adquirir mais conhecimentos e as habilidades técnicas. As disciplinas mais citadas foram Material de Construção e Topografia. Inclusive a disciplina de Topografia ainda não tinha sido cursada pelos alunos do grupo. Citaram que buscaram conhecimentos na literatura e com a experiência de outras pessoas, inclusive professores. Percebeu-se que se valeram também dos conhecimentos adquiridos em Desenho Técnico e Projetivo, pois utilizaram software, maquetes. Além disso, também buscaram contato com empresas para conhecer e adquirir materiais.

Percebeu-se a coesão dos integrantes e conhecimentos adquiridos pela facilidade e fluência em relatar as ações desenvolvidas além de conseguirem avaliar os pontos que podem ser desenvolvidos com mais êxito.

Um dos professores avalia a atividade como "[...] uma forma de despertar o interesse em aprender, pois eles estavam dando início ao seu conhecimento técnico. É forma válida 
de aprendizado" (Professor A). O professor também falou das limitações do trabalho, entre elas a questão financeira.

Ao analisar os relatórios foi possível observar as referências bibliográficas, buscaram conhecimentos na literatura e/ou nas NBR. Foi possível perceber o conhecimento adquirido e disponibilizado nos relatórios.

O olhar dos alunos foi de admiração, contentamento e sentiram-se realizados pela capacidade que adquiriram em planejar, projetar, orçar e executar a obra envolvendo a construção de uma estufa. Sentiram-se engenheiros, desta forma é possível afirmar que sentiram pertencimento ao Curso. Também se sentiram gratos pela possibilidade das discussões e planejamento que poderia ser construído posteriormente.

\section{Considerações finais}

A ação surgiu por uma demanda do curso de Agronomia e pelo interesse dos alunos. Após decisão, existia o desafio de como seria possível construir uma estufa com custo acessível para os pequenos agricultores do município.

Os alunos mantiveram o interesse no desenvolvimento da ação. Entre os conhecimentos adquiridos e os novos conhecimentos conseguiram produzir e aprender. Os alunos foram orientados pelos professores dos dois cursos envolvidos e procuraram outros professores e colegas de semestre finais para compreender como poderiam desenvolver as ações. As discussões e o aprendizado superaram a ação do planejamento e execução da estufa.

O planejamento e a construção da estufa podem ser considerados uma oportunidade extensionista e que atende as orientações das DCNs da Engenharia. Foi possível um olhar para as DCNs e para as demandas locais como uma oportunidade de favorecer o ensino aprendizagem.

Para que as estufas cheguem realmente para os pequenos produtores, a investigação pode ser ampliada com participação de mais professores e cursos e podem envolver ações como uma cooperação entre alguns setores ou seja ampliar um projeto que envolva os setores públicos e privados.

\section{Agradecimentos}

Agradecemos as empresas que contribuíram para o desenvolvimento desse trabalho, em especial a Pedreira Mato Grosso-Pedremat. Também agradecemos a UNEMAT que doou o material e especialmente os acadêmicos do Curso Engenharia Civil envolvidos nos trabalhos.

\section{REFERÊNCIAS}

ASSOCIAÇÃO BRASILEIRA DE NORMAS TÉCNICAS. NBR 16032: Os requisitos para a estrutura de estufa e viveiro agrícola: Requisitos de projeto, construção, manutenção e restauração. 2012.

BRASIL. Conselho Nacional de Educação. Diretrizes Curriculares Nacionais do Curso de Graduação em Engenharia. PARECER CNE/CES №: 1/2019 Despacho do Ministro, publicado no D.O.U. de 23/4/2019, Seção 1, Pág. 109., Brasília, DF, 23 abr. 2019. Disponível em: 
<http://portal.mec.gov.br/index.php?option=com_docman\&view=download\&alias=109871pces001-19-1\&category_slug=marco-2019-pdf\&ltemid=30192>. Acesso em: 1 maio 2021.

CARGNIN-STIELER, Marinez. Educação em engenharia: aspectos da formação pedagógica para o ensino em Engenharia Elétrica. - Ilha Solteira: [s.n.], 2014. 155 f.: il. Disponível em: <http://acervodigital.unesp.br/handle/11449/110514>. Acesso em: 09 de abr. 2021.

CHASSOT, Attico. Alfabetização científica: uma possibilidade para a inclusão social. Rev. Bras. Educ., Rio de Janeiro, n. 22, p. 89-100, Apr. 2003. Available from: $<$ http://www.scielo.br/scielo.php?script=sci_arttext\&pid=S141324782003000100009\&lng=en\&nrm=iso>. Access on: 06 May 2021. http://dx.doi.org/10.1590/S1413-24782003000100009.

CURI, Luiz Roberto Liza Curi. Transformação da educação em Engenharia pela via da política pública. Presidente do CNE. "Documento de Apoio à Implantação das Diretrizes Curriculares Nacionais (DCNs) do Curso de Graduação em Engenharia" 15/06/2020

SANTOS, E. A.; CARVALHO, K. S. A; CARGNIN-STIELER, Marinez. Desenvolvimento de piso permeável como estratégia de aprendizagem nos semestres iniciais de Engenharia Civil. In: Anais do XLIV Congresso Brasileiro de Educação em Engenharia (COBENGE), 2016, Natal. COBENGE 2016. 20 anos de REENGE Caminhos da Engenharia, 2016. p. 1 10.

SANTOS, E. A.; CARGNIN-STIELER, Marinez; WEBER, Guilherme Adriano. Concreto permeável: uma investigação na formação de engenheiros. Brazilian Journal of Development, v. 5, p. 19327-19341, 2019.

SANTOS, E. A.; CARGNIN-STIELER, Marinez; WEBER, Guilherme Adriano. Do projeto a conclusão da calçada permeável: inovação na formação de engenheiros. In: XLVII Congresso Brasileiro de Educação em Engenharia e II Simpósio Internacional de Educação em Engenharia, 2019, Fortaleza. Anais do XLVII Congresso Brasileiro de Educação em Engenharia (COBENGE) e 2 o Simpósio Internacional de Educação em Engenharia da ABENGE' Formação por Competência na Engenharia no Contexto da Globalização 4.0'. Brasília: Abenge, 2019.

SANTOS, E. A.; CARGNIN-STIELER, Marinez; DAMASCENO, M. V. A. Disciplinas básicas na Engenharia Civil pensando sustentabilidade: confecções de tijolos ecológicos com resíduos de britagem e solo argiloso. In: XLVI Congresso Brasileiro de Educação em Engenharia (COBENGE) e 1ำ Simpósio Internacional de Educação em Engenharia da ABENGE, 2018, Salvador. Anais do XLVI Congresso Brasileiro de Educação em Engenharia (COBENGE) e 1 Simpósio Internacional de Educação em Engenharia da ABENGE. Brasília: ABENGE, 2018.

METAUTE PANIAGUA, Piedad María et al. A revitalização das estratégias pedagógicas atuais: uma necessidade aplicável aos processos de ensino e aprendizagem de estudantes de engenharia no século XXI. Rev. Lasallista Investig., Caldas, v. 15, n. 1 pág. 46-56, junho. 2018. Disponível em <http://www.scielo.org.co/scielo.php?script=sci_arttext\&pid=S1794- 
44492018000100046\&lng=es\&nrm=iso >. acesso em: 16 abr. 2021.

https://doi.org/10.22507/rli.v15n1a4

NÓVOA, A. para una formación de profesores construida dentro de la profesión. Revista de Educación, 350. Septiembre-diciembre 2009, pp. 203-21

UNIVERSIDADE DO ESTADO DE MATO GROSSO (UNEMAT). MT Horticultura. Apresentação. Disponível em: < https://www.mthorticultura.com.br/apresentacao/>. Acesso em: 07 abr. 2021.

\title{
ENGINEERING EDUCATION INVOLVING A CONSTRUCTION OF AN AGRICULTURAL GREENHOUSE AS EXTENSION REQUESTS
}

\begin{abstract}
The construction of an agricultural greenhouse is reported as a practical and extension activity with the aim also that students are at the learning centre, with free thinking, critical skills, innovative and entrepreneurial vocation, physical interaction with peers. The initial idea was to offer more appropriate conditions for learning and to encourage students enrolled take place in the Physics subjects of the Civil Engineering course at the State University of Mato Grosso (UNEMAT), University Campus Prof. Eugênio Carlos Stieler in Tangará da Serra. Teaching and learning require a constant rethinking of how to teach so that students feel pleasure from learning to acquire knowledge, critical and social awareness to live better in society. The New Engineering DCNs encourage the use of methodologies that favour active learning, as a way of promoting a more student-centred education. The documents analyzed were the reports, interviews, images, and observations provided by the teachers who accompanied the actions and the public presentation of the work. The actions were positively evaluated, listing learning, knowledge, group work, integration, and support. The students eyes were filled with admiration, contentment and they felt fulfilled by the ability they acquired in planning, designing, budgeting, and executing the work involving the construction of a greenhouse.
\end{abstract}

Keywords: Teaching-learning. Active learning. Critical and social awareness 